\title{
Editorial
}

\section{Intelligent Collaborative Decision-Making Models, Methods, and Tools}

\author{
Goran D. Putnik $\left(\mathbb{D},{ }^{1}\right.$ Leonilde Varela $\mathbb{D},{ }^{1}$ and Vladimír Modrák $\mathbb{D}^{2}$ \\ ${ }^{1}$ University of Minho, Campus of Azurém, Guimarães, Portugal \\ ${ }^{2}$ Technical University of Košice Letná 9, 04200 Košice, Slovakia \\ Correspondence should be addressed to Goran D. Putnik; putnikgd@dps.uminho.pt
}

Received 24 June 2018; Accepted 24 June 2018; Published 5 July 2018

Copyright (C) 2018 Goran D. Putnik et al. This is an open access article distributed under the Creative Commons Attribution License, which permits unrestricted use, distribution, and reproduction in any medium, provided the original work is properly cited.

Problems in engineering are usually hard to be modeled and solved through mathematical approaches, due to the complex nature of these problems and the need for specifying effective, efficient, and proper models to consider and approach reallife or empirical and emulated problem scenarios. Many proposals are constantly being put forward, based on different kind of models, specially referring to mathematical models, and formalization approaches, in the context of this journal, ranging from purely linear programming models, algebra or differential equations based models to artificial intelligent (AI) oriented models or based on agents or neural networks. These include a great number of AI tools, such as fuzzy theory, grey theory, neural network model, Genetic Algorithms, and expert systems.

This special issue addresses intelligent, collaborative decision-making models, methods, and tools for enabling improvements towards collaborative management and the optimization of production activities as well as enhancement of supply chain and networked manufacturing processes. One of the biggest problems arising in the context of engineering and production management science, besides the problem of data collection, is related to information modeling and processing in secure and timely manner. Decision support models and tools have to become increasingly more interactive and accurate across software-based systems intended to support business and organizational decision-making activities in order to help decision makers to compile and process information, specify useful business models and processes, and solve production management problems in companies. The advent of the web and cloud computing have enabled interorganizational decision support systems and have given rise to numerous challenges and applications of existing technology as well as many new decision support models, methods, and technologies.

A number of important works have been carried out during the last decade focusing on these issues, and in this special issue on intelligent, collaborative decision-making models, methods, and tools, a set of papers that further explore this issues are incorporated.

One paper of this special issue addresses a time-variant variance and time-variant expected market demand model to investigate order strategies that are used by risk-averse holiday merchants. Through their newsvendor model, the authors were able to capture the unique characteristics of holiday merchandise in the retail market to investigate the display time and the traditional order quantity decision with time-sensitive purchase cost, therefore helping to offer a more detailed understanding of the interaction among these important parameters through numerical analysis.

Another paper puts forward a plant intelligent behaviour optimization algorithm for solving vehicle routing problem. The algorithm is motivated by intelligent behaviour of plants and is implemented to solve benchmark vehicle routing problems of all sizes. The algorithm is able to be applied to very large vehicle routing problem instances due to the ability of the plant to use previously stored memory to respond to new problems and to adjust to changing problem conditions.

The authors of another paper propose network Data Envelopment Analysis models based on slacks-based measure framework which categorize intermediate measures into 
input or output type endogenously. Moreover, to incorporate inefficiency associated with intermediate measures in efficiency measurement they propose two alternative slacksbased measure models referred to as Model (I) and Model (II), to address the conflict caused by the dual role of intermediate measures, which can be applied to deal with dynamic network models.

Another study presents a cycle deep belief network model for multivariate time series classification, which is a learning algorithm that can discover the structure hidden in the data and learn representations that are more suitable as input to a supervised machine than the raw input. This kind of contributions is quite important as time series classifications are becoming increasingly more important in a broad range of real world applications.

One of the papers of this special issue addresses secure $\mathrm{k}$-nearest neighbors ( $\mathrm{kNN}$ ) computation and integrity assurance of data outsourcing in the cloud. Therefore, the authors propose a verifiable spatial data index structure (VSS-tree) to improve $\mathrm{kNN}$ query efficiency and provide $\mathrm{kNN}$ query verification. Moreover, for resisting level 2 attacks, the cloud server can perform a kNN query on encrypted data points and query points.

Another study puts forward a recommendation approach based on simulation for suggesting optimized production conditions, including processing velocity of the automated machine, to overcome and avoid contamination problems, which can very negatively affect production processes, such as in the case of manufacturing head stack assembly (HSA) within a hard disk drive factory. Therefore, the proposed approach is suitable for recommending sustainable optimized production conditions to provide enhanced environmental conditions, along with improved economical manufacturing conditions, with reduced energy consumptions.

One paper performs an analysis of critical-barriers identification and qualitative data analysis to implement sustainable supply chain management by using interpretive structural modeling technique, based on an empirical case study.

Another paper describes a hybrid algorithm combining simulated annealing and genetic algorithm, referred to as simulated annealing genetic algorithm, along with the application of distributed decision-making and principal-agent theory to build a model for scheduling risk management of IT outsourcing projects.

The authors of one of the papers put forward an agentbased modeling and simulation approach of designer's bidirectional behaviour of task selection in open source design process, based on a website recommendation mechanism through a collaborative filtering algorithm based on a threedimensional matrix including information of design agents, tasks and skills, and an autonomous selection approach, which can be applied in practice benefiting both designers and open source design.

A study of this special issue presents a quite interesting risky multicriteria group decision-making approach based on cloud prospect theory and regret feedback. The approach is based on linguistic variable assessment and proposes a model that considers various and differential psychological behaviour and the ambiguity of linguistic variable assessment across multicriteria risks. Based on the cloud prospect value assessment, a cloud prospect value aggregation method and consensus degree measurement are used. Moreover, an improved feedback adjustment mechanism based on regret theory is employed as the consistency model, which complements prospect theory. The three theoretical methods together constitute the core elements of the authors' proposed cloud prospect value consensus degree decision model.

Goran D. Putnik Leonilde Varela Vladimír Modrák 


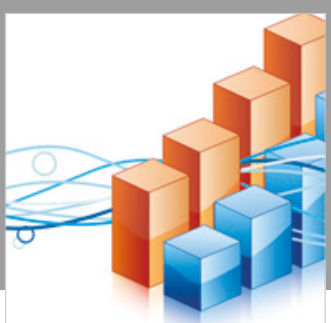

Advances in

Operations Research

\section{-n-m}
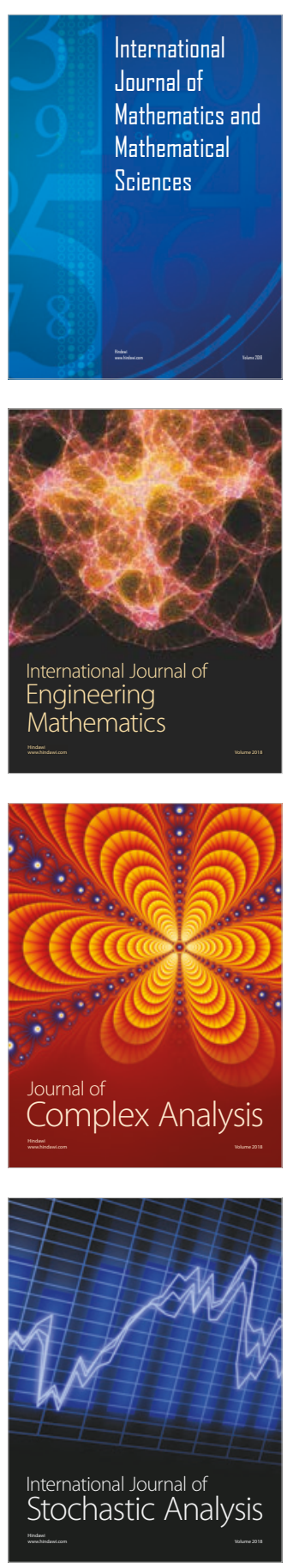
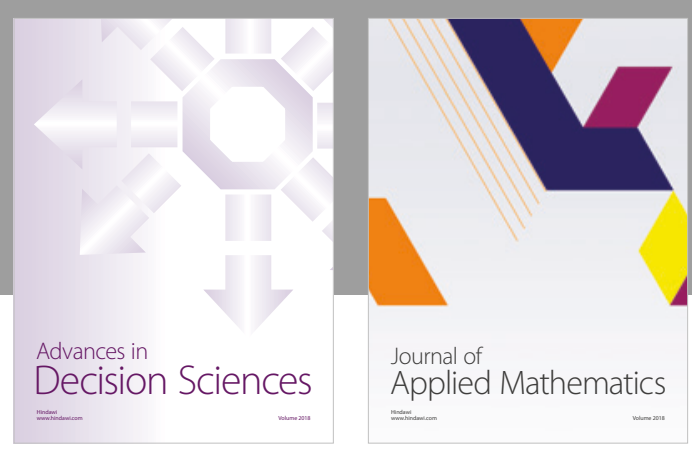

Journal of

Applied Mathematics
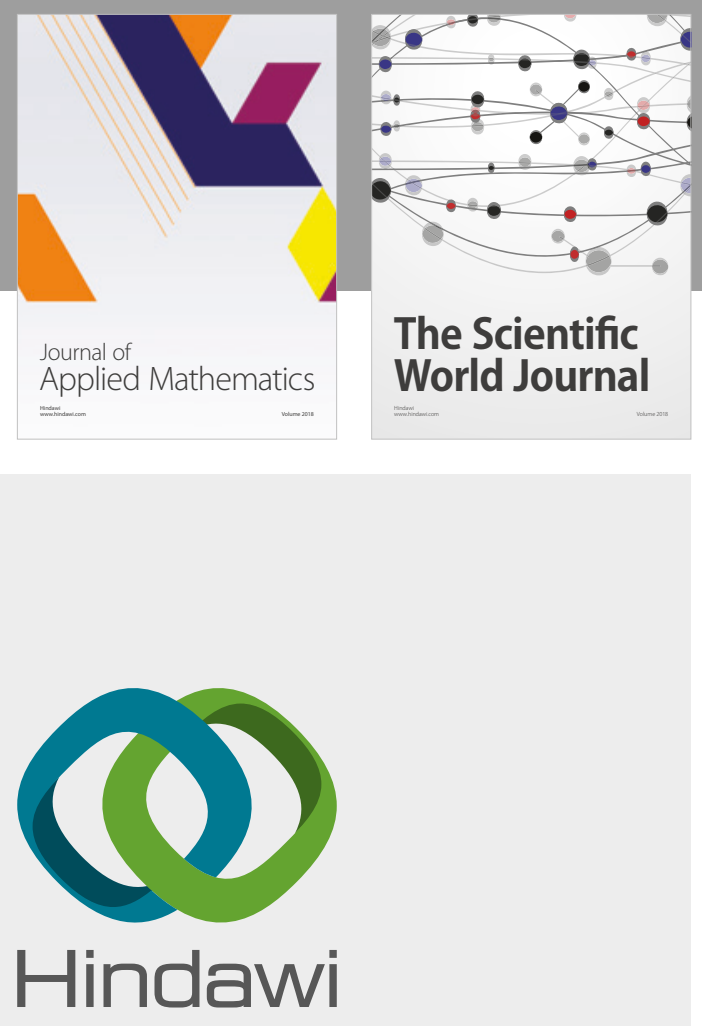

Submit your manuscripts at

www.hindawi.com

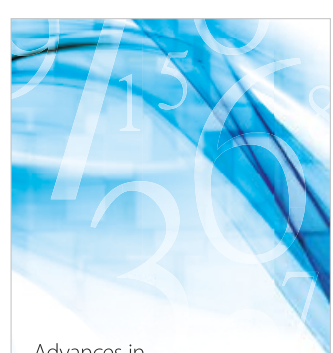

Advances in
Numerical Analysis
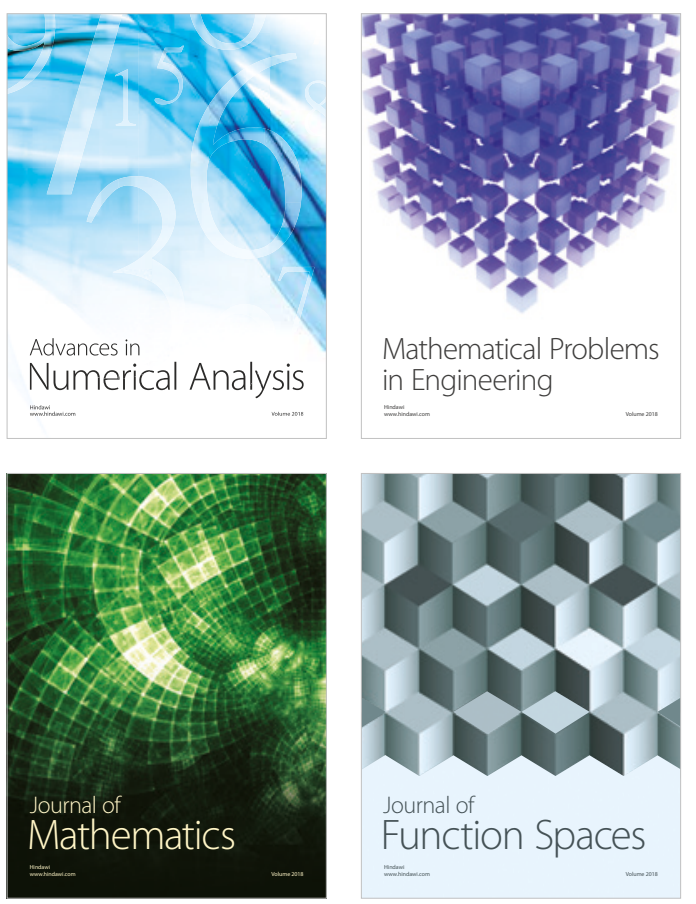

Mathematical Problems in Engineering

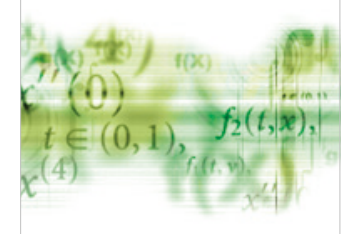

International Journal of

Differential Equations

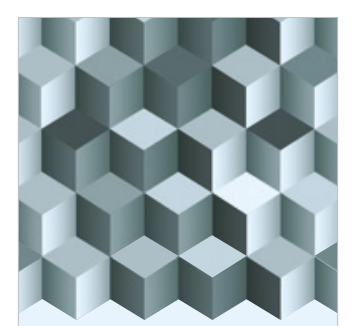

Journal of

Function Spaces

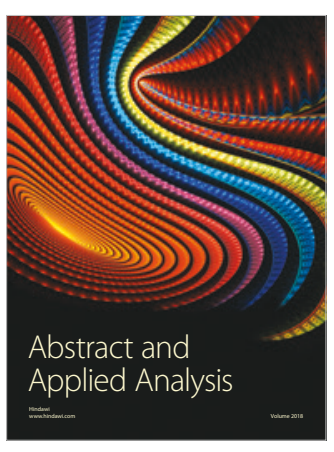

The Scientific

World Journal

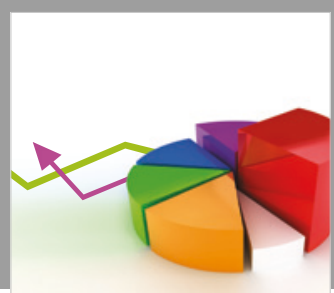

Journal of

Probability and Statistics
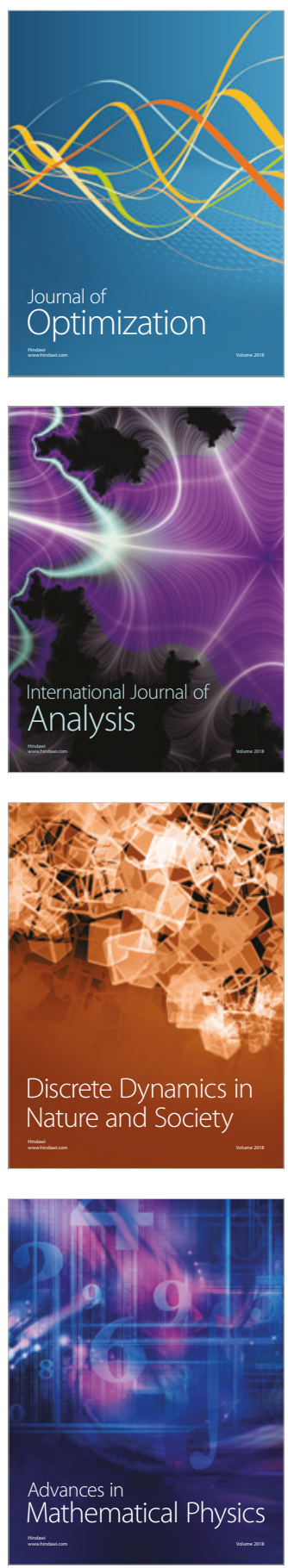